\title{
Contar la transición, o cómo hablar de la china en el zapato. Entrevista a Marta Sanz
}

\author{
Violeta Ros Ferrer
}

UNIVERSITAT DE VALĖNCIA·Violeta.ros@uv.es

Tras casi dos décadas, diez novelas y dos poemarios, en mayo de 2013, Marta Sanz publicó su hasta entonces última novela. Se titulaba Daniela Astor y la caja negra (Anagrama, 2013). Entre otras cosas, la novela recuperaba, desde el imaginario infantil de una niña en 1978, uno de los múltiples y grandes vacíos en el relato de la transición española: el de la mujer que, a finales de los años setenta, es denunciada, juzgada y condenada por llevar a cabo su decisión de abortar.

Este vacío en el relato, este episodio no contado, es una de las múltiples teselas que integran el gesto de reconstrucción de una narración colectiva y compleja del proceso transicional en España. Algunas de estas teselas, incómodas en su mayoría, y que hacen que contar la historia sea un poco más difícil, aún están a la espera de ser narradas. "Nosotros no podemos convertir esta historia en un silencio - leemos hacia el final de la novela-porque el silencio es un modo de subrayar las cosas, pero también de borrarlas".

Justo un año después de la publicación de Daniela Astor y la caja negra, en mayo de 2014, la editorial Anagrama reeditaba La lección de anatomía (2008). Esta vez, Marta Sanz contaba la historia de Marta Sanz, pero el escenario seguía siendo el mismo: los años de un proceso de cambio político, económico y cultural que coinciden en el tiempo con el proceso de formación e inserción en la vida adulta de toda una generación que, ahora, empieza a construir su propia narración de aquellos años. Otra tesela más en la construcción de este relato colectivo.

Trasladar de forma crítica este escenario vital propio al plano común de la construcción de ficciones literarias. Crear narradores que permitan hablar de lo incómodo. Contar lo que falta ser contado y pensado. Hablar de la china en el zapato. Este es el rasgo de honestidad intelectual que hace de la producción narrativa de la autora un proyecto éticamente comprometido con su presente.

DOI: 10.7203/KAM.4.4409 
KAMCHATKA: Son muchas las novelas que, de un tiempo a esta parte, han tratado de acercarse al periodo de cambio político en España desde la ficción. Pensamos en novelas como Lo real (Anagrama, 2001), El día del Watusi, (Destino 2003) El vano ayer (Seix Barral, 2004), Anatomía de un instante (Mondadori, 2009), Paseos con mi madre (Tusquets, 2011), Todo está perdonado (Tusquets, 2011), El jardín colgante, (Seix Barral, 2012) o Daniela Astor y la caja negra (Anagrama, 2013), entre muchas otras. Estas novelas proponen volver la vista atrás, hacia acontecimientos, polémicas, formas de vida o incluso recuerdos de los años 60, 70 y 80 en España. Desde tu punto de vista, ¿cómo se está modificando el gran relato de la transición en la literatura de los últimos años? En términos generales, ¿considerarías que ha habido una voluntad de cuestionar o, al menos, de contarlo de otra manera desde la novela?

MARTA SANZ: Los autores nacidos en las décadas de los sesenta y de los setenta nos hemos criado con el relato épico de la Transición española que tan persistentemente se publicitó desde los medios de comunicación y las instancias políticas. La idea de una Transición ejemplar, incruenta, exportable como modelo de cambio para otras dictaduras. Frente a ese discurso oficial era necesario generar otro tipo de narraciones, probablemente más violentas y descarnadas, que quizá abren las heridas cerradas en falso y vuelven a poner ciertos muertos encima de la mesa: las víctimas de los francotiradores en las manifestaciones, los asesinados por grupúsculos fascistas, la esperanza combinada con el miedo que fermentaba en un sentimiento muy extraño en las casas de los militantes. Y poco a poco la pérdida de la euforia y el entusiasmo. Los escritores que recuperamos ese momento histórico lo hacemos desde el análisis y la preocupación política por el presente. Me parece que no queremos caer en un ejercicio de nostalgia, sino en mostrar cómo de aquellas lluvias llegaron estos lodos. Acabo de ver una película La isla mínima de Alberto Rodríguez que, entre otras cosas, cuenta cómo el tránsito hacia la democracia se produjo sin la correspondiente depuración de las fuerzas de seguridad del Estado y cómo esa omisión conciliadora imposibilitó el normal funcionamiento de instituciones que son intrínsecamente represivas: las manzanas podridas, los torturadores, se humanizan, amparados en un colectivo que los acepta pese a las máculas del pasado, y a la vez que recuperan su rostro humano normalizan la brutalidad en un estado de derecho en construcción. Resulta estremecedor que ahora salgan a la luz historias como las de los niños robados que, hoy por hoy, inspiran multitud de series de televisión que hacen de la anécdota algo espectacular o melodramático. Productos que no invitan a la reflexión sobre un periodo de nuestra historia reciente sobre el que aún tenemos muchas preguntas que responder.

Desde un punto de vista literario, funciona una metáfora muy potente en las narraciones sobre la Transición escritas por los nacidos en las dos décadas antes citadas: nuestra pubertad, nuestra metamorfosis social y sexual, coincide con la supuesta metamorfosis de un país que, con el tránsito hacia la democracia, llega a su mayoría de edad. Las incertidumbres, los miedos y las esperanzas, las expectativas y los temores constituyen un estado de conciencia individual y colectiva, biográfica e histórica, que resulta muy sugerente a la hora de escribir. También la idea de que la memoria siempre es 
el relato de la memoria y ese relato nunca es unívoco ni unilateral: está hecho de una diversidad de fragmentos y miradas que lamentablemente en el caso de la Transición se emborronaron con una mirada dominante idílica y publicitaria.

KAMCHATKA: Más allá del mercado, de la mediatización del propio debate transicional y de las secuelas del boom de la memoria en literatura, ¿considerarías que este tipo de novelas están aportando formas de narrar el pasado sustancialmente diferentes a las propuestas narrativas surgidas desde finales de los 80 hasta finales de los 90 ?

MARTA SANZ: Algunas sí. Otras no.

Kaмchatka: En tu libro de ensayos No tan incendiario (Periférica, 2014), defiendes que los géneros literarios deberían estar en constante transformación, en la misma medida en que lo están las propias ideas. De este modo, apuntas, se evita que acaben por convertirse en meros recipientes de ideologías dominantes. Si tuvieras que escoger una, ¿qué novela de los últimos años considerarías que ha problematizado el mito de la transición desde una voluntad explícitamente formal de transformar los propios códigos del género?

MARTa SANZ: Una de las ideas fundamentales de No tan incendiario es la de que la forma es ideológica: las formas de prestigio o las formas populares en un determinado corte de la historia están condicionadas por el discurso dominante que, en el tiempo que nos ha tocado vivir, es el neoliberalismo, la ideología del Sillicon Valley y esa cosa aterradora, dulce e intrínsecamente violenta que se llama capitalismo filantrópico. Desde esta perspectiva, todos los productos culturales de éxito podrían ser objeto de desconfianza por parte de receptores críticos. Se trata de cuestionar la idea neoliberal de la cultura como producto, de la cultura como espectáculo y del lector como cliente al que hay que complacer. Se trata de arriesgarse a no complacer generando artefactos que provoquen inquietud, incomodidad hablando del precio de las patatas, de las máculas de la realidad, a través de géneros y de propuestas retóricas que inviten a la reflexión, que irriten, que descoloquen a los receptores. Por el cómo y por el qué de la propuesta. Sincrónica e indisolublemente. Se trata de intervenir "modestamente" en la realidad y en el propio estatus de la literatura a través de las historias que contamos cuestionando, por ejemplo, la frase hecha de que las novelas han de "contar historias". En este sentido, yo creo que novelas como El vano ayer son absolutamente ejemplares.

KAмChatKa: Sobre la cuestión generacional. Hace unas semanas Costantino Bértolo publicaba un artículo en la revista El Estado Mental donde problematizaba las implicaciones ideológicas del debate literario en clave generacional. Más allá de los problemas que presenta el propio hecho de dividir la producción literaria en generaciones, en el caso de las novelas que ficcionalizan episodios o aspectos concretos de la transición 
desde el presente, la polémica literaria parece solaparse con un momento en el que se está produciendo un relevo generacional de las voces en relación a un cierto relato histórico. ¿Cómo te posicionarías en este debate?

MARTA SANZ: Creo que lo que hace Bértolo interviniendo en ese debate es procurar que no se usurpe el significado de ciertas palabras y conceptos. Que no se suavice a Marx para hacerlo "digerible" y "digestivo" en un mundo donde la violencia se ejerce desde el poder, pero está estigmatizada si se ejerce desde cualquier otro lugar. Bértolo busca que no se despolitice a Marx y que conceptos como "lucha de clases" y "clase" no se utilicen desde una perspectiva light. Y resulta instructivo que sea un hombre de la generación de Bértolo quien tome la palabra en un debate que se produce en el seno de una generación que vive en un mundo brutal y que se enzarza en polémicas violentísimas y a menudo huecas por ocupar un pequeño espacio en el campillo literario -el concepto "campillo literario" también es de Bértolo- mientras que, en lo más profundo de nuestro ADN ideológico, llevamos impresa la marca de la docilidad.

KAмСHATKA: El núcleo ficcional de Daniela Astor y la caja negra (Anagrama, 2013) cuenta la historia de una mujer que, a finales de los años setenta, decide abortar contra la voluntad de su marido. La novela se publica en mayo de 2013, más o menos en el mismo periodo de tiempo en que el ex Ministro de Justicia Alberto Ruiz Gallardón presenta su

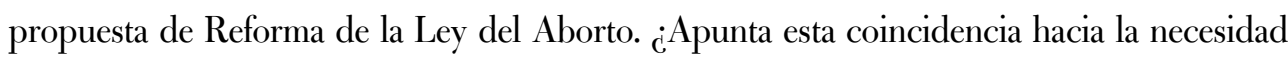
de una violencia simbólica ejercida a través de la literatura como respuesta a un contexto intrínsecamente violento, por oposición a la idea de la cultura como herramienta al servicio del consenso?

MARTa SANZ: Querida Violeta, yo no podría haberlo dicho mejor que tú.

KAMCHATKA: En uno de sus libros, Jacques Rancière subrayaba la noción de desacuerdo como el elemento constitutivo de la noción de democracia y, al mismo tiempo, señalaba su ausencia como una falta estructural en las socialdemocracias contemporáneas. ¿Qué papel crees que ha jugado la cultura, y en especial cierto tipo de novelas, en la desactivación de esa necesaria dosis de desacuerdo en el caso de la cultura de la socialdemocracia española, particularmente en relación con el mito de la transición? Y, en concreto, ¿qué papel crees que han jugado ciertos novelistas canónicos, especialmente en relación con las formas de memoria que han propuesto desde la literatura?

MARTA SANZ: Frente a la obsesión posmoderna por disolver dicotomías, "conceptualmente espurias", que colocan el lenguaje, la hiperonimia y las figuras retóricas en un primer plano de la polémica política y literaria, creo que debemos aportar argumentos para recuperar la relación antitética entre los conceptos como vida/literatura (Munro, Yourcenar, y la evidencia de que en último término todo cae del lado de la vida y de la realidad, todo termina formando parte de nosotros y nosotros no somos papel ni hombre de lata: carne, sangre y víscera, un elevadísimo porcentaje de agua mineral sin gas) 
realidad/ficción; publicidad/crítica; víctima/verdugo; revolución/evolución y/o regeneracionismo; gobierno/empresa; marketing/filantropía (el caso de Coca-cola y los acuíferos en la India); padre/amigo; centro/periferia; autor/lector; lo autobiográfico/lo imaginativo... Al final, yo tengo la sospecha de que la desactivación del desacuerdo, el reblandecimiento del límite y el prestigio de la labilidad y la morbilidad -ideológica y textual-, así como de eslóganes tan queridos por la crítica literaria como el de "la verdad de la mentiras", tienen como objetivo último la construcción de una falacia políticamente interesada: la de que no existe la dicotomía rico/pobre -incluso la dicotomía izquierda/derecha- en un momento en el que en Occidente se acentúa la brecha de la desigualdad.

La "democracia digital"; los productos y la iconografía de Sillicon Valley; el desprestigio de los contenidos; el desplazamiento del foco de atención desde los modos ideológicos de decir hacia el soporte -supuestamente aséptico y ecuménico- de la elocución digital; o los procesos de beatificación mediática de santos laicos como Steve Jobs son las puntas del iceberg de un discurso hegemónico: el neoliberalismo. Se trata de poner de manifiesto esas nuevas formas de autoritarismo enmascarado, que paradójicamente son asumidas por escritores y activistas de izquierda mientras se devalúan conceptos como democracia y educación, y se lima la posibilidad transformadora de los proyectos culturales. Tal vez, con un sentido del humor que sea carcajada y no ironía, deberíamos enriquecer nuestro léxico con palabras que ahora nos aterran: lo apocalíptico y lo integrado, o el ludismo del temerario Capitán Swing... Yo creo que sería conveniente evidenciar los límites y las contradicciones subrayando en rojo la existencia de fronteras reales que no pueden difuminarse ni convertirse en eufemismo por mucho que lo mestizo, lo heterogéneo, lo mutante, lo queer, lo flexible y lo polivalente, los gallifantes y los abejonejos, sean valores consagrados por la publicidad. Como se decía en el anuncio de Coca-cola: "Para los de arriba, para los de abajo; para los gordos, para los flacos..." Mi propia producción literaria utiliza a veces las consignas violentas de esa falsa labilidad. Porque, aunque posiblemente sea la única actividad reflexiva y creativa que merezca la pena, resulta muy difícil hacer un ejercicio de abstracción de las coordenadas ideológicas del tiempo que a uno le toca vivir para sacar a la luz los elementos de esa ideología invisible que es como La carta robada de Poe: precisamente por tenerla delante de los ojos, no la podemos ver. Tal vez, más allá de profilaxis y proteccionismos extremos -como los que se practican con los niños- haya que restablecer la dimensión positiva del conflicto como elemento de cambio y crecimiento.

KAMCHATKA: La construcción narrativa de Daniela Astor y la caja negra provoca un choque de relatos. Por un lado, está la narración del drama familiar desde la perspectiva infantil de Daniela Astor y, por otro, está el discurso cultural sobre el cine del destape que propone el documental La caja negra. ¿Hacia dónde quieres apuntar con esta puesta en paralelo de discursos?

MARTA SANZ: Hacia la relación que existe entre la realidad y sus representaciones, entre el yo construido -en este caso de las mujeres- y la iconografía cultural sobre las 
mujeres. Hacia la idea de que la cultura nunca es aséptica ni inofensiva. Siempre forma, siempre condiciona, siempre transmite valores, creencias y actitudes que son obviamente ideológicos y constituyen el ingrediente fundamental de lo que aspiramos a ser como individuos. En el caso de esa novela se habla de cómo una adolescente en el año 78 en España tiene una visión de sí misma, una aspiración, un deseo de performatividad física y sentimental, que pasa por su asimilación del imaginario de las actrices del destape.

KAMCHATKA: En la mayoría de tus novelas la voz que narra se construye desde una marcada primera persona, de carácter autobiográfico. De hecho, la Catalina de Daniela Astor y la caja negra recuerda bastante a la Martita de La lección de anatomía, y en ambas novelas tiene mucho peso la interacción y la evolución de esa niña que narra desde la mujer adulta con el contexto concreto de los años 70 y 80 en España. ¿Cómo funciona el elemento autobiográfico, en relación con el contexto histórico en el que se enmarca, dentro de la construcción de estas dos novelas?

Marta Sanz: En Daniela Astor y la caja negra el elemento autobiográfico se reduce al hecho de que en la novela se retrata un contexto cultural que yo comparto con Catalina, la protagonista del libro. En La lección de anatomía el asunto es un poco más complejo porque Marta, la protagonista narradora de la novela, se presenta desnuda ante el lector con la conciencia de que no hay mayor pose que la de mostrarse desnudo y a la vez sabiendo que las poses, como gesto, son enormemente reveladoras. En los dos casos, se parte de la idea de que intimidad y la identidad no son lo mismo: de que somos lo que somos por cuestiones genéticas, familiares, de cuarto de estar y de mesa camilla, pero que sobre todo somos lo que somos por lo que compartimos con nuestra comunidad, por el momento histórico que nos toca vivir, por los lugares comunes que forman parte de nosotros... Me interesa construir relatos y retratos donde lo importante no es la idiosincrasia personal, lo individual, lo singular o lo excéntrico, sino la idea de que lo personal, lo individual, lo singular y lo excéntrico solo tienen sentido en lo común. Tal vez por eso, la presencia de la historia es tan importante en mis novelas.

KAMCHATKA: ¿Consideras que una voz narrativa femenina $-o$, al menos, destestosteronizada- puede aportar algo específico a la hora de proponer un relato alternativo, o de rescatar una parte del relato silenciado, tratándose, especialmente, de un relato tan cerrado -y, en ocasiones, quizás demasiado fálico- como es el de los años de la transición?

Marta SanZ: Yo creo en la diferencia entre los hombres y las mujeres. Somos construcciones diferentes desde un punto de vista biológico e histórico. Por supuesto político. El hecho de asumir que la diferencia existe -igual que existe una diferencia entre ricos y pobres, o entre analfabetos e ilustrados- no significa que yo quiera que tal diferencia se convierta en desventaja. Ahora me interesa mucho cómo se conectan los polos débiles de las oposiciones reales: mujeres, pobres, analfabetos... Me interesa porque es una conexión que tiene que ver con el injusto funcionamiento de las cosas hoy y desde tiempos 
inmemoriales. Tener conciencia de esa desventaja es el modo de poder cambiar. Me parecen dañinos los espejismos de igualdad, las fantasías de que no existen los límites. Vivimos inmersos en una poética de la labilidad, de lo líquido, de lo fronterizo que es ideológicamente interesada en la medida en que pretende limar las aristas de conflictos que tendrían que estallar si queremos que las cosas cambien. Me gusta la metáfora de que hay que romper las lunas de los escaparates: me encantaría que mis libros surtiesen ese efecto.

Desde esa perspectiva, tanto los escritores como las escritoras tenemos formación y habilidad para impostar voces ajenas, construir ambientes, dialogar en un libro, narrar con estilo violento, almibarado, abigarrado, desnudo o ampuloso en función de lo que queramos contar. Sin embargo, creo que las mujeres, por razones de desventaja histórica e incluso de justa ira, vamos a enfocar temáticamente asuntos que quizá los hombres no han sentido nunca como chinas en el zapato y nosotras sí. Yo escribo de lo que me duele. Por otro lado, esa misma desventaja histórica nos coloca en la posición de intentar ser más agresivas respecto a los géneros tradicionales de comunicación social: los géneros en los que nos hemos formado y con los que nos hemos construido, pero en los que solo hemos llevado la voz cantante de forma minoritaria y a menudo mimética con el lenguaje del poder. Esa mímesis con el discurso dominante masculino era tal vez la única forma de ser valorada, integrada, en un canon expulsivo para nosotras. Fracturar los géneros, fracturar el lenguaje, escribir feo de lo feo, es un posicionamiento ideológico que posiblemente ahora sea más reconocible en la escritura femenina. Aunque no siempre, también hay escritoras muy conservadoras desde todos los puntos de vista. 